\title{
Factors influencing unmet need for contraception amongst adolescent girls and women in Cambodia
}

\author{
Farwa Rizvi ${ }^{\text {Corresp., } 1}{ }^{\text {, Joanne Williams }}{ }^{2}$, Steven Bowe ${ }^{3}$, Elizabeth Hoban ${ }^{4}$ \\ ${ }^{1}$ Faculty of Health, School of Health and Social Development, Deakin University, Burwood, Victoria, Australia \\ 2 Department of Health Sciences and Biostatistics, Faculty of Health, Arts \& Design, Swinburne University of Technology, Hawthorne, Victoria, Australia \\ 3 Deakin Biostatistics unit, Faculty of Health, School of Health and Social Development, Deakin University, Burwood, Victoria, Australia \\ ${ }^{4}$ Consultant at Faculty of Health, School of Health and Social Development, Deakin University, Burwood, Victoria, Australia \\ Corresponding Author: Farwa Rizvi \\ Email address: rizvifa@deakin.edu.au
}

Background: Unmet need is the gap between women's need and their practice of using contraception. Unmet need for contraception in female youth in Cambodia is a public health concern which may lead to unintended pregnancies or abortions that can contribute to maternal morbidity and mortality. Methods: Bronfenbrenner's Social Ecological Model was used as a theoretical framework to analyze data from the 2014 Cambodian Demographic and Health Survey to ascertain demographic and social factors potentially associated with unmet need for contraception. Bivariate and weighted multiple logistic regression analyses with adjusted odds ratios (AOR) were conducted for 4,823 Cambodian, sexually active females aged 15-29 years. Results: The percentage of unmet need for contraception was $11.7 \%$. At the individual level of Social Ecological Model, there was an increased likelihood of unmet need in adolescent girls 15-19 years and women 20-24 years. Unmet need was decreased in currently employed women. At the microenvironment level, there was an increased likelihood of unmet need with husband's desire for more children and when the decision for a woman's access to healthcare was made by someone else in the household. At the macroenvironment level, unmet need was decreased in women who could access a health facility near their residence to obtain medical care. There were no urban rural differences found in the Cambodian sample population. Conclusion: Unmet need for contraception in Cambodian females is associated with younger age, unemployment and low personal autonomy for accessing healthcare but not with education or wealth status. There is a need to implement culturally appropriate reproductive and sexual health literacy programs to increase access to modern contraception and to raise women's autonomy. 


\section{Factors influencing unmet need for contraception}

3 amongst adolescent girls and women in Cambodia

6 Farwa Rizvi ${ }^{1}$, Joanne Williams ${ }^{2}$, Steve J Bowe ${ }^{3}$, Elizabeth Hoban ${ }^{4}$

$7{ }^{1}$ Faculty of Health, School of Health and Social Development, Deakin University, Burwood,

8 Victoria Australia

92 Department of Health Sciences and Biostatistics, Faculty of Health, Arts \& Design, 218

10 Hawthorn 3122, VIC Australia

$11{ }^{3}$ Deakin Biostatistics Unit, Faculty of Health, School of Health and Social Development, Deakin

12 University, Geelong, Victoria Australia

$13{ }^{4}$ Consultant at Faculty of Health, School of Health and Social Development, Deakin University, 14 Burwood, Victoria Australia

Corresponding Author:

17 Farwa Rizvi ${ }^{1}$

18 Faculty of Health, School of Health and Social Development, Deakin University, 221 Burwood Highway, Burwood 3125, Victoria Australia

\section{Abstract}

Background: Unmet need is the gap between women's need and their practice of using contraception. Unmet need for contraception in female youth in Cambodia is a public health concern which may lead to unintended pregnancies or abortions that can contribute to maternal morbidity and mortality.

Methods: Bronfenbrenner's Social Ecological Model was used as a theoretical framework to analyze data from the 2014 Cambodian Demographic and Health Survey to ascertain demographic and social factors potentially associated with unmet need for contraception. Bivariate and weighted multiple logistic regression analyses with adjusted odds ratios (AOR) were conducted for 4,823 Cambodian, sexually active females aged 15-29 years.

Results: The percentage of unmet need for contraception was $11.7 \%$. At the individual level of Social Ecological Model, there was an increased likelihood of unmet need in adolescent girls 15- 
19 years and women 20-24 years. Unmet need was decreased in currently employed women. At the microenvironment level, there was an increased likelihood of unmet need with husband's desire for more children and when the decision for a woman's access to healthcare was made by someone else in the household. At the macroenvironment level, unmet need was decreased in women who could access a health facility near their residence to obtain medical care. There were no urban rural differences found in the Cambodian sample population.

Conclusion: Unmet need for contraception in Cambodian females is associated with younger age, unemployment and low personal autonomy for accessing healthcare but not with education or wealth status. There is a need to implement culturally appropriate reproductive and sexual health literacy and services programs to increase access to modern contraception, reduce child marriages, and to raise adolescent girls and women's autonomy.

Key words: Adolescent; Contraception; Personal Autonomy; Family Planning; Reproductive and Sexual Health; Unintended Pregnancies

\section{Introduction}

Unmet need for contraception is the gap between women's desire for family planning and their practice of using contraception methods (Bradley et al. 2012). The international conference on population and development (ICPD) as coordinated by the United Nations Population Fund (UNFPA) was held in 1994 in Cairo (UNFPA 1994). At the centre of the ICPD consensus has been the call for a global commitment to sexual and reproductive health rights and access to family planning for women, gender equality, and women empowerment which are pivotal for sustainable development (Kanem 2019). In 2015, the United Nations proposed the Sustainable Development Goals (SDGs) which include a set of 17 goals with 169 associated targets to be reached by 2030 (UN 2015). Universal access to sexual and reproductive health (SRH), including accessibility to contraception is an important goal for SDGs 2030 (UN 2015). 
65 Sustainable Development Goal (SDG) 3 focuses on good health and well-being at all ages and 66 the target 3.7 of SDG 3 specifically focuses on providing SRH services (UN 2015).

67 Cambodia is a low income, agricultural country located in the South-East Asian region,

bordering Thailand, Laos, and Vietnam (DHS, CNIS \& ICF 2015). Cambodia's turbulent political history in the past few decades has been a major reason for a slow progress towards improving the country's reproductive health parameters (Field et al. 2011). The birth spacing policy in Cambodia was introduced in 1995 as part of the national family planning program in the wake of the ICPD in 1994 (UNFPA 1994; WHO 2017). The Cambodian national population policy was introduced in 2003 (Vong 2008). Despite the efforts made by the Cambodian family planning program, the current contraception prevalence rate for modern contraception methods is 39\% (DHS, CNIS \& ICF 2015). This indicates a large gap between women's knowledge and their practice of contraception use (WHO 2017). World Health Organisation (WHO) reports that $30 \%$ of married Cambodian women of childbearing age (15-49 years) do not want to become pregnant, but they either do not use any contraception methods or use traditional methods (WHO 2017).

Unmet need for contraception in females in Cambodia and other low-to-middle-income countries (LMICs) is associated with sexually transmitted infections (STIs), unintended pregnancies and unsafe abortions as a result of risky sexual behavior or unsafe sex which contribute to maternal morbidity and mortality (Hegde, Hoban \& Nevill 2012; Rizvi et al. 2020; Sedgh, Ashford \& Hussain 2016b). Bradley et al in 2012 proposed a revised algorithm to calculate unmet need for the Demographic Health Surveys (DHS) including a complex measurement of 15 survey items (USAID 2015). The result was described as the percentage of sexually active women of childbearing age, and couples who would prefer to space or limit the next pregnancy but are not 
88 using any contraception methods (Bradley et al. 2012). The DHS are conducted globally since 89 1984, providing nation-wide data in the areas of population, health, and nutrition in LMICs for 90 purposes of monitoring and evaluation programs (USAID 2015).

91 Gender inequality is one of the challenges to sustainable development in most LMICs in East-Asia and South-East Asia, including Cambodia, Myanmar, Lao PDR, Timor-Leste, Indonesia, Vietnam and the Philippines (UNICEF 2019). The disproportionate burden of SRH issues and high unmet need in female adolescents and young people in Cambodia and other LMICs in the Asia-Pacific region is often made worse by lack of health literacy, and non-existent SRH services (ChandraMouli et al. 2019; Rizvi et al. 2020; Sedgh, Ashford \& Hussain 2016a). There is strong research evidence for integrated SRH literacy and family planning services, and increased number of schools with improved education and targeted interventions to reduce school dropouts especially for female adolescents (Azzopardi et al. 2019). These interventions include monetary inducements to parents and youth, free school uniforms and provisions, and employment opportunities along with achieving gender equity (Azzopardi et al. 2019; Sheehan et al. 2017; UNFPA 2019; UNICEF 2019). Past and current research strongly supports reducing child marriages in LMICs, including disadvantaged groups such as ethnic minorities, migrants and displaced youth (Azzopardi et al. 2019; UNFPA 2019).

Identification of multiple factors influencing unmet need in Cambodian females presents an opportunity to implement a holistic SRH program to improve contraception rates for reducing unintended pregnancies. This is linked to improving universal access to SRH and contraception in particular, which is an objective for the SDG 3 for good health and wellbeing (UN 2015). The concept of SRH and rights proposed by Starrs et al (2018) in the Lancet includes the state of complete physical, mental and social wellbeing pertaining to sexuality and the reproductive 
111 system (Starrs et al. 2018). All individuals have a right to make informed decisions about their

112 reproductive bodies and be able to access the SRH services (Starrs et al. 2018). The definition of

113 SRH rights encompasses women's autonomy, eradication of gender violence, respect for

114 reproductive body functions, and the relevant services and interventions which are required to

115 address individuals' SRH needs for their overall well-being (Starrs et al. 2018; UNFPA 2019).

116 Box 1 provides an overview of the policy implications.

\section{Theoretical Framework}

118 This study is theory based and uses the modified social ecological model (SEM) by Koren and 119 Mawn (2010) and Rizvi et al (2019) as adapted from Bronfenbrenner's SEM (Bronfenbrenner 120 1979; Koren \& Mawn 2010; Rizvi, Williams \& Hoban 2019). The social ecological model for 121 unmet need includes factors operating at three levels including individual, microenvironment, 122 and macroenvironment (Bronfenbrenner 1979; Rizvi, Williams \& Hoban 2019). These multiple 123 factors at different levels can influence a woman's behaviour patterns for using contraception 124 methods (Bronfenbrenner 1979). The individual level includes personal characteristics like age, 125 sociodemographic details including area of residence (urban or rural), occupation, and education.

126 The microenvironment level includes interpersonal and societal factors like family, friends and 127 partners; and the macroenvironment level includes relevant policy laws and regulations, media 128 messages for family planning, distance from the health care facilities (Bronfenbrenner 1979;

129 Rizvi, Williams \& Hoban 2019). Using the SEM model provides an understanding of the various 130 factors concurrently functioning at multiple levels and their association with the unmet need, as 131 well as the identification of prospective gaps in knowledge.

\section{Aim}


133 The primary aim was to determine the social and demographic factors influencing unmet need

134 for contraception at the individual, microenvironment and the macroenvironment levels amongst

135 Cambodian sexually active 15-19 years old adolescent girls and 20-29 years old women using

136 the social ecological model.

\section{Materials \& Methods}

138

139

140

141

142

143

144

The 2014 Cambodian Demographic and Health Survey (CDHS) is the latest, nationally represented survey which provides countrywide data (DHS, CNIS \& ICF 2015). This is the first study in Cambodia to use the dataset from the 2014 CDHS. Weighted data analyses were performed to ascertain factors influencing unmet need in 4823 Cambodian sexually active females aged 15-29 years. The revised definition from 2012 DHS was used for unmet need for contraception (Bradley et al. 2012). The sampling frame including the list of enumeration areas (EAs) was provided by the Cambodian National Institute of Statistics (DHS, CNIS \& ICF 2015). Two-stage stratified sampling and probability systematic sampling were used for participants selection (DHS, CNIS \& ICF 2015). All the details for the survey methodology are already mentioned by Rizvi et al (2019) (Rizvi, Williams \& Hoban 2019). The data used in our study came from the 2014 CDHS individual questionnaire (DHS, CNIS \& ICF 2015).

\section{Ethics}

The 2014 CDHS dataset is freely available with deidentified information from the website for DHS program 'https:/www.dhsprogram.com/data/available-datasets.cfm' (USAID). The dataset was analysed after receiving approval from MEASURE head office for the DHS program (USAID), and ethics exemption was obtained from the 'Deakin University Human Research Ethics Committee (DUHREC)', Victoria, Australia (project no 2018-157). The 2014 CDHS 
156 adhered to the legal requirements of Cambodia and received ethics permission from the

157 Cambodian Ministry of Health and written informed consent was obtained from all participants

158 before undertaking the survey. Additional information about 2014 CDHS can be obtained from

159 the Cambodian Ministry of Health (Cambodia 2017).

\section{Important definitions}

\section{Contraceptive prevalence rate (CPR)}

162 Percentage of sexually active women of reproductive age group aged 15-49 years (married or in

163 a sexual union), who are currently using, or whose partner is currently using any family planning

164 (FP) method at a specific point in time (Bradley et al. 2012).

\section{Unmet need for contraception as the outcome (dependent variable)}

Percentage of sexually active women of reproductive age group aged 15-49 years (married or in sexual union) and couples who would prefer to space or limit the next pregnancy but are not using any contraceptive methods (Bradley et al. 2012). Unmet need for contraception is the sum of both the unmet need for spacing and for limiting pregnancies (Bradley et al. 2012; USAID 2015). Women with an unmet need for spacing wish to delay the next birth for a specified time (at least two years) but they are not using any contraception (USAID 2015). Women with an unmet need for limiting do not want any (more) children but they are not using any contraception (USAID 2015). A set of 15 different questions from the DHS made up the complex calculation of unmet need (USAID 2015).

\section{Identification of sexually active females from the dataset of 2014 CDHS}


176 Those females aged 15-29 years who gave a positive response to the question 'age at first sex'

177 were classified as sexually active.

\section{Multiple independent variables}

179 The following independent categorical variables were identified in the literature as likely 180 predictors, and are included in the multiple logistic regression model (Petitet \& Desclaux ;

181 Samandari, Speizer \& O'Connell 2010b). The variables at the individual level of SEM

182 (Bronfenbrenner 1979) included; three age groups in years (15-19, 20-24, 25-29), area of

183 residence (rural and urban), current employment status (yes/no), parity (continuous variable).

184 The variables under microenvironment level included; person in the household deciding about

185 woman's access to healthcare and person in the household deciding about major household items

186 purchase (woman herself, joint decision of woman and husband, husband only, someone else in

187 the household indicating the mother-in-law/parents-in-law), husband's wish for children (both

188 husband and wife want same number of children, husband wants more children, husband wants

189 less children, husband does not know). Variables under the macroenvironment included;

190 listening to any government sponsored media messages about family planning on radio (yes/no),

191 and on television (yes/no) in the past three months, ability to access a nearby health care facility

192 (not difficult/very difficult), participant told about family planning at the health facility (yes/no).

\section{Statistical analyses}

194 The analyses included descriptive, bivariate analyses and binary logistic regression using the

195 Stata SE version 15.1. A P-value $<0.05$ was considered statistically significant. The bivariate

196 analyses included Pearson's chi square tests used for cross-tabulations to determine the degree of

197 association between unmet need and each categorical variable. To adjust for survey cluster 
198 sampling, survey weights were applied. The odds ratios (OR) with 95\% confidence interval (CI)

199 were reported for binary logistic regression analyses showing adjusted OR (AOR). We used a

200 forward and backward elimination approach for our model. There were missing values of 407

201 women in the data for two independent variables, "person who decides for access to healthcare

202 for the woman' and 'person who decides to purchase the major household items'. These missing

203 values were listwise deleted, and the AOR were reported for a total of 4416 sexually active

204 women. There was no significant difference in the unmet need in urban or rural regions. Post-

205 estimation diagnostic tests such as ROC curves and Hosmer-Lemeshow's goodness of fit tests

206 were applied (Peng, Lee \& Ingersoll 2002).

\section{Results}

The personal, social and demographic characteristics of participants aged 15-29 years are

presented in Table 1. The sample included 4823 participants, including $1329(27.5 \%)$ urban and $3494(72.4 \%)$ rural females (15-29 years). The sample shows $44.6 \%$ of females with primary education, $40.4 \%$ with secondary education and $10.1 \%$ with no education. The descriptive analyses show that $458(89.4 \%)$ adolescent girls aged $15-19$ years were already married at the time of survey and 67\% of females aged 15-29 years were currently employed (Table 1). The results after applying binary logistic regression are shown under the social ecological model (SEM) (Bronfenbrenner 1979) in a flow chart in Fig 1.

Table 2 shows bivariate analyses using Pearson's Chi-square test used for cross-tabulations to determine the degree of association between unmet need and each categorical variable. It was noted that bivariate analyses, and Crude Odds Ratio (COR) were non-significant for the variables, 'education', and 'wealth index', so these two variables were not included in the binary logistic regression analyses. The binary logistic regression analyses results $(n=4416)$ are 
222 presented in Table 3. The results from descriptive, bivariate and binary logistic regression

223 analyses are presented under the individual, microenvironment and macroenvironment levels of

224 SEM (Bronfenbrenner 1979).

\section{Individual level of SEM}

226 a. Knowledge of ovulation days in menstrual cycle

227 The participants either did not know or had incorrect information about their ovulation days

228 during menstrual cycles (76.5\%) (Table 1$)$.

229 b. Contraceptive prevalence rate (CPR)

230 The contraceptive prevalence rate (CPR) for traditional and modern methods was 49\%. Modern

231 contraceptive prevalence rate was $35.4 \%$ and traditional contraceptive prevalence rate was

$23213.6 \%$. The contraception use in the three age groups of adolescent girls aged 15-19 years, young

233 women aged 20-24 years and 25-29-year-old women is shown in Table 1.

234 c. Unmet need for contraception

235 The unmet need was $11.7 \%$ which was the sum of unmet need for spacing $(9.4 \%)$ plus unmet

236 need for limiting (2.3\%). The highest unmet need was in adolescents aged 15-19-years (15.2\%),

237 followed by women aged 20-24 years (12.1\%), and 25-29 years (10.5\%) (Table 1$)$.

238 The results from bivariate analyses using Pearson Chi-square test in Table 2 show that P-value

239 was significant $(\mathrm{P}=0.01)$ for unmet need for the following variables; age groups, employment

240 status, parity, husband's desire for family size, and the variable for 'person deciding for purchase

241 of major house-hold items'.

242 Binary logistic regression analyses show that there was an increased likelihood of unmet need in

243 the younger age groups including adolescent girls aged $15-19$ years $(\mathrm{AOR}=1.9,95 \% \mathrm{CI}=1.3-2.8)$ 
244 and women aged 20-24 years $(\mathrm{AOR}=1.4,95 \% \mathrm{CI}=1.1-1.8)$ compared to the women in their late

245 twenties (25-29 years) (Table 3$)$.

246 d. Total number of children ever born/parity

247 There were $20.2 \%$ of women with no children, $69.8 \%$ of women had $1-2$ children, and $10 \%$ of

248 women had 3 or more children (Table1). Unmet need was significantly associated with

249 increasing parity $(\mathrm{P}=0.001)$ (Table 2$)$. The binary logistic regression shows increased likelihood

250 of unmet need with multiparity (Table 3).

251 e. Employment

252 Sixty-seven percent of women were currently employed (Table 1). Bivariate analyses show

253 significant association ( $\mathrm{P}=0.001)$ of unmet need with employment status (Table 2$)$. There was a

254 decreased likelihood of unmet need in currently employed females aged 15-29 years (AOR=0.6,

$25595 \% \mathrm{CI}=0.5-0.8)($ Table 3$)$.

\section{Microenvironment level of SEM}

257 a. Person making decision for women's access to healthcare

258 Table 1 shows the frequency distribution of females aged 15-29 years for the decision to access

259 healthcare. There was an increased likelihood of unmet need when someone else in the

260 household decided about the woman's access to healthcare (AOR=2.0, 95\% CI=1.1-4.1). That

261 person could be either the mother-in-law or the parents-in-law (Table 3).

262 b. Husband's desire for children

263 Descriptive analyses show that $66.6 \%$ of couples wanted the same number of children, whereas

$26417.1 \%$ of husbands wanted more children (Table 1). Bivariate analyses show significant

265 association $(\mathrm{P}=0.01)$ between unmet need and decision for family size (Table 2$)$. There was an 
266 increased likelihood of unmet need if the woman's husband wanted more children (AOR=1.3,

$26795 \% \mathrm{CI}=1.01-1.8)$ (Table 3).

268 c. Woman's lack of autonomy to ask her husband to use a condom

269 Descriptive analyses show that $323(7.2 \%)$ participants reportedly could not demand condom use

270 from their partner or husband at the time of sexual intercourse, and $316(7.1 \%)$ were not sure if

271 they could ask their husband to use condoms (Table 1).

\section{Macroenvironment level of SEM}

273 a. Distance to health care facility and getting medical help

274 Descriptive analyses show 1663 (34.5\%) women reported that accessing a nearby health care

275 facility for medical help was very difficult, compared to $3160(65.5 \%)$ women who reported that

276 it was not a big problem (Table 1). There was a decreased likelihood of unmet need in females

277 aged 15-29 years who could easily access health care facility nearby to obtain medical care for

278 themselves $(\mathrm{AOR}=0.8,95 \% \mathrm{CI}=0.6-1.0)($ see Table 3$)$.

\section{Discussion}

281 Adolescent girls and young women aged 15-24 years in Cambodia are more susceptible to

282 having unmet need for contraception. The likelihood of unmet need is also increased in

283 adolescent girls and women under 30 years of age with accessibility issues to a nearby health

284 care facility and low personal autonomy when their access to healthcare is decided by someone

285 else such as the mother-in-law, or the parents-in-law. Unmet need is increased in women with

286 low financial autonomy who are unemployed, and with low reproductive health autonomy when

287 their husbands want more children. 
288

289

290

291

292

293

294

295

296

297

298

299

300

301

302

303

304

305

306

307

308

309

\section{Individual level of SEM}

There is an increased trend of unmet need (15.2\%) in Cambodian adolescent girls aged 15-19 years. Similar findings were shown in the analyses of the 2011 Bangladesh DHS data with a higher trend of unmet need (17\%) in female adolescents aged 15-19 years and youth aged 20-24 years (Islam, Mostofa \& Islam 2016). Wulifan et al (2015) in a scoping review of unmet need in 34 quantitative and qualitative studies in low-to-middle-income countries (LMICs) reported that unmet need is increased in adolescent girls and women below the age of 34 years, especially in Zambia and Nepal (Wulifan et al. 2015).

Our results show increased unmet need in women with multiparity. We propose that Cambodian younger women have an increased likelihood of unmet need as they are married either in their adolescence (child brides) or early twenties and are under social pressure to have early and repeat pregnancies. Our data shows that $89.4 \%$ of adolescent girls aged $15-19$ years were already married at the time of the survey. In Cambodia, one in four women are already married by age 18 years, and half of the women are married by age 20.5 years (DHS, CNIS \& ICF 2015). Coll et al (2019) analysed data from 73 LMICs and reported that many of the child brides wish to delay the first birth, or want birth spacing, but these adolescent girls are influenced by the society norms for early child bearing (Coll et al. 2019). Rizvi et al (2019) report that Cambodian adolescent girls and women 15-29 years have low personal autonomy to access healthcare which can lead to an increased likelihood of having an unintended pregnancy (Rizvi, Williams \& Hoban 2019). Reducing child marriages, decreasing unmet need by improving adolescents' access to SRH and modern contraception can break the cycle of adolescent pregnancies and repeat, unintended pregnancies (UNFPA 2019). 
310 Women who have current, paid employment have a decreased likelihood of having unmet need.

311 We posit that women who are currently employed could have an intrinsic motivation to use

312 contraception to avoid an unintended pregnancy or abortion, thus ensuring their earning

313 potential. This is an indicator of financial autonomy and could translate to an improved

314 reproductive health autonomy in women and result in the increased use of modern contraception

315 methods. Wulifan et al (2015) and Rizvi et al (2019) suggest that women who are currently

316 employed may want to space or limit their future pregnancies to allow continued gainful

317 employment, especially in urban families (Rizvi, Williams \& Hoban 2019; Wulifan et al. 2015).

318 Conversely, Sedgh et al (2014) show that unemployed women usually have limited or no

319 financial autonomy, which can translate into increased gender inequality and low reproductive

320 health autonomy (Sedgh \& Hussain 2014). The United Nations Children's Fund (UNICEF)

321 reports gender inequality in employment, education or training (NEET) in adolescent girls and

322 women compared to boys and men, in LMICs due to pre-conceived gender roles allocating

323 unpaid domestic chores and care work to women, and paid work to the men (UNICEF 2019).

324 Studies suggest that unemployed women usually depend on their husband or partner's income

325 and may have low decision-making ability for their SRH matters including non-use, or

326 infrequent use of contraception (Sedgh \& Hussain 2014; Wulifan et al. 2015).

327 Our study did not show any significant association of formal education levels and wealth status

with unmet need. One likely explanation could be the low secondary school completion rate for

329 girls in Cambodia, as most young girls leave school after primary education (UNFPA \& CNIS

331 girls compared to adolescent boys (UNFPA \& CNIS 2016; UNICEF 2019). Another reason

332 could be an absence of a holistic SRH literacy program inculcated in Cambodian schools' 
333 curriculum. So these youth could not make an informed decision to use contraception as they did

334 not have the SRH literacy despite attaining formal education. Some studies from LMICs show

335 different results. Haq et al (2017) from Bangladesh report that higher education level and wealth

336 status in adolescent girls and women was significantly associated with increased contraception

337 use (Haq, Sakib \& Talukder 2017). In contrast, Ngome et al (2014) report that in Zimbabwe,

338 adolescents 15-19 years with a higher education level were less inclined to use contraception

339 (Ngome \& Odimegwu 2014).

\section{Microenvironment level of SEM}

341 Unmet need for contraception is significantly increased in women when someone else in the

342 household decides about their access to healthcare, thus reducing their personal autonomy. We

343 posit that health-seeking behaviours in these younger females are deeply influenced by the

344 ingrained societal norms which originate from a patriarchal culture. Studies from Cambodia, as

345 well as from many LMICs in Asia, and some African countries show that women's decision to

346 access health care, including contraception, are usually made either by their husband or by

347 another family member (elder) in the household (Chandra-Mouli et al. 2014; Gupta et al. 2015;

348 Rizvi, Williams \& Hoban 2019; Samandari 2010). In many situations it is the mother-in-law, or

349 the father-in-law who make these decisions (Gupta et al. 2015). As a result, these females have

350 low or non-existent decision-making ability regarding contraceptive use (Coll et al. 2019). Phan

351 (2016) used DHS data from four South-East Asian countries including the Philippines,

352 Cambodia, Indonesia, and Timore-Leste, and reported that employment, education status, and

353 house-hold decision making autonomy were the three factors which consistently affected

354 women's empowerment (Phan 2016). The Sustainable Development Goals (SDGs) especially 
355 SDG 3 and 5 put emphasis on human rights, women empowerment and the right of young girls

356 and women to achieve gender equality and access to health (WHO 2015).

357 Our results show an increased likelihood of unmet need if the husband wanted more children,

358 indicating that woman's desire for birth spacing or for a smaller family size is not considered.

359 We posit a lack of communication about the desired family size between the husband and wife.

360 Melese et al (2016) found in a study in Ethiopia that the husband's wish for children is

361 significantly associated with increased unmet need and subsequent unintended pregnancy (Getu

362 Melese et al. 2016). The reason could be sociocultural as children are considered as wealth in the

363 community (Getu Melese et al. 2016). A study in Cambodia by Hukin (2014) reported similar

364 perceptions amongst most men and elders, noting that having more children is considered to

365 increase the financial support and family networking, and it balances the burden of care for the

366 parents (Hukin 2014). Similar findings are reported by Samandari et al (2010) who noted that the

367 likelihood of Cambodian women using effective contraception increased three times if their

368 husbands wanted a smaller family (Samandari, Speizer \& O'Connell 2010b). We recommend a

369 holistic SRH program which involves the couples, and the elders in the household to improve

370 awareness and communication about desired family size and use of effective modern

371 contraception. Health education programs need to take into consideration a collective decision-

372 making approach by the women, husbands and elders in the household when designing SRH and

373 family planning campaigns (Gupta et al. 2015; Samandari, Speizer \& O'Connell 2010b). Studies

374 from Cambodia and multiple qualitative studies from LMICs in South-East Asia and Central

375 Asia have also reported that communication amongst the husband and wife about the ideal

376 number of children, and the husband's support for use of effective contraception can decrease the

377 unmet need (Samandari, Speizer \& O'Connell 2010a; Wulifan et al. 2015). 


\section{Macroenvironment level of SEM}

379 In our study, females aged 15-29 years had low unmet need if they could physically access a

380 nearby health care facility to obtain SRH care and contraception. A proportion of women

$381(34.5 \%)$ found it very difficult to access a health care facility close to their place of residence.

382 Previous studies from Cambodia show that some young women due to their migrant status reside

383 in the low socioeconomic peri-urban areas with limited access to modern contraception and SRH

384 services at the healthcare facilities (Peou 2016; Webber et al. 2015). In Cambodia and most other

385 LMICs, there is a social stigma pertaining to the adolescents' sexual behaviour and pre-marital

386 sex (Peou 2016; Webber et al. 2015). This manifests as reluctance on the part of the healthcare

387 personnel in providing SRH information and services to the adolescents and youth (Peou 2016;

388 Webber et al. 2015). Young people are also hesitant to seek SRH care for fear of being

389 recognised in the community by the healthcare personnel (Peou 2016; Webber et al. 2015). There

390 is a dearth of person-centred SRH and counselling at the healthcare facilities for the women in

391 Cambodia. This indicates an opportunity to train the healthcare personnel at various government

392 and private facilities by increasing their communication skills with youth for SRH education.

393 Azzopardi et al (2019) recommend providing mandatory education about SRH and the range of

394 modern contraception methods to the male and female youth coming into the health centres as

395 part of the adolescent and youth friendly family planning services at the global level (Azzopardi

396 et al. 2019). There is a strong need to provide long-acting reversible contraceptives (LARCs)

397 including subdermal implants at the various health centres and pharmacies in Cambodia

398 (Bajracharya et al. 2016). The subdermal implants are safe and effective for 3-5 years without

399 the need for repeat visits for resupply, but these are still underutilised in Cambodian females

400 (Bajracharya et al. 2016). The multiple barriers for modern contraception use in Cambodia need 
401 to be addressed at the user, healthcare personnel, health systems, and policy levels (Bajracharya 402 et al. 2016).

403 At the moment, there is no SRH literacy program for adolescents and youth, especially the out404 of-school adolescents and young people in Cambodia (UNFPA 2015). It is imperative to ensure 405 that adolescents and young people are given a place at the table to discuss their SRH needs, make 406 informed decisions and that they are provided with accurate SRH information (Chandra-Mouli et 407 al. 2019). Cambodia has $80 \%$ of population in the rural region (DHS, CNIS \& ICF 2015). A 408 local organisation, Reproductive Health Association of Cambodia (RHAC) in Cambodia sends

409

410

411

412 413 weekly messages about SRH and contraception as part of an outreach program to a few villages in Takeo Province on remork-moto (UNFPA 2014). Remork-moto is a two wheeled vehicle managed by a single driver (UNFPA 2014). Many rural people, usually adolescent girls and women attend the community education sessions for SRH conducted by community based team leaders in collaboration with RHAC (UNFPA 2014). Young people need to be informed about the availability and range of SRH services in the community and health centres by trained health care personnel, selected community members, outreach workers, preferably adolescents and youth themselves (WHO 2012). The community awareness and information sessions about SRH and contraception could be replicated at a larger level in Cambodia in partnership with Cambodian government and multiple international and national organisations who are already working in Cambodia. Some of these organisations include World Health Organisation (WHO), United Nations Population Fund (UNFPA), Population Council, Population Services International (PSI), RHAC, Reproductive and Child Health Alliance (RACHA) (UNFPA 2014, 2015; WHO 2017). Slaymaker et al (2020) recommend focusing on the social-structural determinants influencing the use of modern contraception in adolescent girls and women 
424 (Slaymaker et al. 2020). A good infrastructure is required for enhancing research capacity,

425 ongoing training of local stake holders and holistic development of health systems (Beran et al.

426 2017). There is a need for continued collaboration with diverse partners and stake-holders to

427 work towards increased gender equitable environment in Cambodia.

\section{Conclusions}

429 Multiple factors influence unmet need in Cambodian females, including younger age groups, unemployment, and decreased accessibility to SRH services. The social norms in Cambodian society dictate a low or non-existent personal and reproductive health autonomy in sexually active adolescent girls and women in their twenties. In the married women, this could be partly explained by a lack of communication in the couple for SRH, contraception use, and desired number of children which is influenced by the role of husband or parents-in-law. Our study results concur with the existing literature for LMICs and contribute to the gaps in literature on unmet need amongst sexually active single and married Cambodian females.

\section{Limitations}

438 The study is based on cross sectional data which cannot determine causality. However, the results help us to ascertain the factors influencing unmet need in Cambodian females at different levels of the social ecological model. The study focus has been on females only, which includes sexually active single and married adolescents and women who are under 30 years, as the negative consequences of unmet need in terms of unintended pregnancies and induced abortions are higher in these age groups. Future studies should include the perspectives of Cambodian males about SRH and contraception to better understand the factors that may play a role in unmet 445 need.

\section{Recommendations}


447 Sexual and reproductive health literacy, education, and employment opportunities to 448 improve gender equality

449 There is a need for adoption of culturally sensitive, accessible and multipronged SRH literacy 450 program and holistic family planning services for adolescents and youth, including continuous

451 monitoring and evaluation strategies. Policies need to be implemented for decreasing the gender 452 gaps in male and female youth, men and women for formal education, and meaningful 453 employment opportunities in the society.

\section{Focus on awareness and availability of modern contraceptives}

455 Focused efforts are needed to promote increased condom use as it gives dual protection from 456 sexually transmitted infections (STIs) and unintended pregnancies. There is a need to remove

457 barriers at the user and supply side for the provision of modern, short-acting contraception 458 methods including oral pills and LARCs such as subdermal implants. The subdermal implants 459 should be made available at the pharmacies and health centres in Cambodia to the female youth 460 and women. A voucher scheme could be started as part of family planning program especially 461 for making the subdermal implants financially accessible to young Cambodian women.

\section{Reducing child marriages}

Robust policy and legal frameworks need to be implemented for reducing child marriages, 464 adolescent pregnancies, and improving access to modern contraception for youth. These youth include both at-school and out-of-school and at-risk or displaced young females in the community.

One way to reduce child marriages could be to implement policies and regulations for providing 
469 schools. There is a need for a linking program for adolescents' SRH and referrals between schools

470 and health centres in Cambodia.

471 Dissemination of SRH information via social media and community-outreach programs

472 There is a good window of opportunity for a targeted SRH program for Cambodian youth about

473 the advantages of modern contraception. These SRH messages could be publicised via social

474 media platform and electronic media. This could include awareness campaigns in the form of

475 mobile-phone text messages as part of sponsored family planning program by Cambodian

476 government. The hard-to-reach, rural youth could be sent the SRH and family planning messages

477 via remork-moto as part of the community outreach program. Young people could be selected

478 from the community for SRH training purposes and employed on casual basis for the outreach

479 programs.

480 Adolescent and youth friendly SRH services

481 Policies need to be implemented for the accessible, affordable, and acceptable contraception

482 provision for youth as part of the SRH program. There is a need for multi-tiered implementation

483 of targeted, evidence-based protocols and record-keeping for adolescent and youth friendly SRH

484 services. The SRH services centres need to ensure privacy, confidentiality and swift

485 consultancies for all young people with minimum waiting time. There could be trainers working

486 in tandem with the healthcare personnel to ensure communication skills with young people, and

487 channels of referral as a part of linking program between schools and health facilities, and

488 program evaluation for improvements.

Adolescents coming to the health centres should be provided with information material for SRH

490 and modern contraception and told about family planning methods by trained healthcare 
491 personnel. The education and information material should be displayed as posters and available

492 as booklets and leaflets for young people. Cambodia can achieve the targets set for Sustainable

493 Development Goal 3 as proposed by the United Nations for gender equality, and improved

494 personal, financial and reproductive health autonomy of women by increasing social awareness

495 amongst youth, women, and men. We recommend robust local governance, improved leadership,

496 ensuring participation of adolescents and youth in the community programs for SRH, and

497 accountability at all hierarchical levels.

498

499

500

501

502

503

504

505

506

507

508

509

510

511

512

513

514

515

516

517

518

519

520

521

522

523

524
Azzopardi, PS, Hearps, SJ, Francis, KL, Kennedy, EC, Mokdad, AH, Kassebaum, NJ, Lim, S, Irvine, CM, Vos, T \& Brown, AD 2019, 'Progress in adolescent health and wellbeing: tracking 12 headline indicators for 195 countries and territories, 1990-2016', The Lancet, vol. 393, no. 10176, pp. 1101-18.

Bajracharya, A, Veasnakiry, L, Rathavy, T \& Bellows, B 2016, 'Increasing uptake of long-acting reversible contraceptives in Cambodia through a voucher program: evidence from a difference-in-differences analysis', Global Health: Science and Practice, vol. 4, no. Suppl. 2, pp. S109-S21.

Beran, D, Byass, P, Gbakima, A, Kahn, K, Sankoh, O, Tollman, S, Witham, M \& Davies, J 2017, 'Research capacity building-obligations for global health partners', The Lancet Global Health, vol. 5, no. 6, pp. e567-e8.

Bradley, SE, Croft, TN, Fishel, JD \& Westoff, CF 2012, 'Revising unmet need for family planning'.

Bronfenbrenner, U 1979, The ecology of human development, Harvard University press. DOI: https://khoerulanwarbk.files.wordpress.com/2015/08/urie_bronfenbrenner_the_ecology_of_human_d evelopbokos-z1.pdf.

Cambodia, NloS 2017, National Institute of Statistics. Ministry of Planning, Phnom Penh.

Chandra-Mouli, V, McCarraher, DR, Phillips, SJ, Williamson, NE \& Hainsworth, G 2014, 'Contraception for adolescents in low and middle income countries: needs, barriers, and access', Reproductive health, vol. 11 , no. 1 , pp. 1-8.

Peer) reviewing PDF | (2020:05:48994:1:2:NEW 15 Aug 2020) 
525

526

527

528

529

530

531

532

533

534

535

536

537

538

539

540

541

542

543

544

545

546

547

548

549

550

551

552

553

554

555

556

557

558

559

560

561

562

563

564

565

Chandra-Mouli, V, Plasons, M, Barua, A, Mohan, A, Melles-Brewer, M \& Engel, D 2019, 'Adolescent sexual and reproductive health and rights: a stock-taking and call-to-action on the 25th anniversary of the ICPD', Sexual and Reproductive Health Matters, vol. 27, no. 1, pp. 336-9.

Coll, CdVN, Ewerling, F, Hellwig, F \& de Barros, AJD 2019, 'Contraception in adolescence: the influence of parity and marital status on contraceptive use in 73 low-and middle-income countries', Reproductive Health, vol. 16, no. 1, p. 21.

DHS, CNIS \& ICF 2015, Cambodia Demographic and Health Survey 2014. National Institute of Statistics/Cambodia, Directorate General for Health/Cambodia, ICF International, The DHS Program, ICF International, Rockville, Maryland, USA. DOI: https://dhsprogram.com/pubs/pdf/FR312/FR312.pdf.

Field, NP, Om, C, Kim, T \& Vorn, S 2011, 'Parental styles in second generation effects of genocide stemming from the Khmer Rouge regime in Cambodia', Attachment \& human development, vol. 13, no. 6, pp. 611-28.

Getu Melese, K, Gebrie, MH, Berta Badi, M \& Fekadu Mersha, W 2016, 'Unintended pregnancy in Ethiopia: community based cross-sectional study', Obstetrics and Gynecology International, vol. 2016.

Gupta, ML, Aborigo, RA, Adongo, PB, Rominski, S, Hodgson, A, Engmann, CM \& Moyer, CA 2015, 'Grandmothers as gatekeepers? The role of grandmothers in influencing health-seeking for mothers and newborns in rural northern Ghana', Global public health, vol. 10, no. 9, pp. 1078-91.

Haq, I, Sakib, S \& Talukder, A 2017, 'Sociodemographic factors on contraceptive use among ever-married women of reproductive age: evidence from three demographic and health surveys in Bangladesh', Medical Sciences, vol. 5, no. 4, p. 31.

Hegde, S, Hoban, E \& Nevill, A 2012, 'Unsafe abortion as a birth control method: maternal mortality risks among unmarried Cambodian migrant women on the Thai-Cambodia border', Asia-Pacific Journal of Public Health, vol. 24, no. 6, pp. 989-1001.

Hukin, E 2014, 'Cambodia's Fertility Transition: The Dynamics of Contemporary Childbearing', Population And Development Review, vol. 40, no. 4, pp. 605-28.

Islam, AZ, Mostofa, MG \& Islam, MA 2016, 'Factors affecting unmet need for contraception among currently married fecund young women in Bangladesh', The European Journal of Contraception \& Reproductive Health Care, vol. 21, no. 6, pp. 443-8.

Kanem, N 2019, 'The battle for sexual and reproductive health and rights for all', Sexual and Reproductive Health Matters, vol. 27, no. 1, pp. 323-5.

Peer] reviewing PDF | (2020:05:48994:1:2:NEW 15 Aug 2020) 
566 Koren, A \& Mawn, B 2010, 'The context of unintended pregnancy among married women in the USA', 567 BMJ Sexual \& Reproductive Health, vol. 36, no. 3, pp. 150-8.

568

569

570

571

572

573

574

575

576

577

578

579

580

581

582

583

584

585

586

587

588

589

590

591

592

593

594

595

596

597

598

599

600

601

602

603

604

605

\begin{abstract}
Ngome, E \& Odimegwu, C 2014, 'The social context of adolescent women's use of modern
\end{abstract} contraceptives in Zimbabwe: a multilevel analysis', Reproductive health, vol. 11, no. 1, p. 64.

Peng, C-YJ, Lee, KL \& Ingersoll, GM 2002, 'An introduction to logistic regression analysis and reporting', The journal of educational research, vol. 96, no. 1, pp. 3-14.

Peou, C 2016, 'Negotiating rural-urban transformation and life course fluidity: Rural young people and urban sojourn in contemporary Cambodia', J. Rural Stud, vol. 44, pp. 177-86.

Petitet, PH \& Desclaux, A 'Reproductive Health and HIV in Cambodia From Anthropology to Public Health 2010. Available at: https://hal-riip.archives-

ouvertes.fr/file/index/docid/584295/filename/Hancart_Desclaux_2010.pdf'.

Phan, L 2016, 'Measuring women's empowerment at household level using DHS data of four Southeast Asian countries', Social Indicators Research, vol. 126, no. 1, pp. 359-78.

Rizvi, F, Williams, J \& Hoban, E 2019, 'Factors Influencing Unintended Pregnancies amongst Adolescent Girls and Young Women in Cambodia', International Journal of Environmental Research and Public Health, vol. 16, no. 20, pp. 1-15. DOI: https://doi.org/0.3390/ijerph16204006.

Rizvi, F, Williams, J, Maheen, H \& Hoban, E 2020, 'Using Social Ecological Theory to Identify Factors Associated With Risky Sexual Behavior in Cambodian Adolescent Girls and Young Women Aged 10 to 24 Years: A Systematic Review', Asia Pacific Journal of Public Health, vol. 32, no. 2-3, pp. 71-80.

Samandari, G 2010, 'Contraceptive use in Cambodia: A multi-method examination of determinants and barriers to modern contraception', ProQuest Information \& Learning.

Samandari, G, Speizer, IS \& O'Connell, K 2010a, 'The role of social support and parity in contraceptive use in Cambodia', International perspectives on sexual and reproductive health, vol. 36, no. 3, pp. 12231.

Samandari, G, Speizer, IS \& O'Connell, K 2010b, 'The role of social support and parity on contraceptive use in Cambodia', International perspectives on sexual and reproductive health, pp. 122-31.

Sedgh, G, Ashford, LS \& Hussain, R 2016a, Unmet need for contraception in developing countries: examining women's reasons for not using a method, Guttmacher Institute, New York.

Peer) reviewing PDF | (2020:05:48994:1:2:NEW 15 Aug 2020) 
606

607

608

609

610

611

612

613

614

615

616

617

618

619

620

621

622

623

624

625

626

627

628

629

630

631

632

633

634

635

636

637

638

639

640

641

642

643

644

645

646

Sedgh, G, Ashford, LS \& Hussain, R 2016b, 'Unmet need for contraception in developing countries: examining Women's reasons for not using a method', New York: Guttmacher Institute, vol. 2, pp. 2015-6.

Sedgh, G \& Hussain, R 2014, 'Reasons for contraceptive nonuse among women having unmet need for contraception in developing countries', Studies in Family Planning, vol. 45, no. 2, pp. 151-69.

Sheehan, P, Sweeny, K, Rasmussen, B, Wils, A, Friedman, HS, Mahon, J, Patton, GC, Sawyer, SM, Howard, E \& Symons, J 2017, 'Building the foundations for sustainable development: a case for global investment in the capabilities of adolescents', The Lancet, vol. 390, no. 10104, pp. 1792-806.

Slaymaker, E, Scott, RH, Palmer, MJ, Palla, L, Marston, M, Gonsalves, L, Say, L \& Wellings, K 2020, 'Trends in sexual activity and demand for and use of modern contraceptive methods in 74 countries: a

retrospective analysis of nationally representative surveys', The Lancet Global Health, vol. 8, pp. 567-79.

Starrs, AM, Ezeh, AC, Barker, G, Basu, A, Bertrand, JT, Blum, R, Coll-Seck, AM, Grover, A, Laski, L \& Roa, M 2018, 'Accelerate progress-sexual and reproductive health and rights for all: report of the Guttmacher-Lancet Commission', The Lancet, vol. 391, no. 10140, pp. 2642-92.

\section{UN 2015, Sustainable Development Goals (SDGs) Knowledge Platform-United Nations-Department of} Economic and Social Affairs. , <https://sustainabledevelopment.un.org/sdgs>.

UNFPA 1994, International Conference on Population and Development (ICPD) United Nations Population Fund <https://www.unfpa.org/icpd>.

UNFPA 2014, Remork-motos to deliver mobile family planning messages and services, United Nations Population Fund <https://cambodia.unfpa.org/publications/unfpa-supports-remork-motos-delivermobile-family-planning-messages-and-services?page $=0 \% 2 \mathrm{CO} \% 2 \mathrm{C} 2>$.

UNFPA 2015, Program of Cooperation between The Royal Government of Cambodia and the United Nations Population Fund 2016-2018, Country Program Action Plan (CPAP)

<www.cdc-crdb.gov.kh/...Programs/.../cpap.../Draft Cambodia CPAP 2016 2018.pdf>.

UNFPA 2019, Sexual and Reproductive Health and Rights: An Essential Element of Universal Health Coverage. Background document for the Nairobi Summit on ICPD 25 - Accelerating the promise., $<$ https://www.unfpa.org/featured-publication/sexual-and-reproductive-health-and-rights-essentialelement-universal-health>.

UNFPA \& CNIS 2016, Sexual and Reproductive Health of Adolescents and Youth in Cambodia. Analysis of 2000 - 2014 Cambodia Demographic and Health Survey Data, UNFPA and National Institute of Statistics Cambodia <https://cambodia.unfpa.org/sites/default/files/pubpdf/UNFPA Final Report 10 October 2016 5pm\%28NRT reformated\%29.pdf>.

Peer] reviewing PDF | (2020:05:48994:1:2:NEW 15 Aug 2020) 
647

648

649

650

651

652

653

654

655

656

657

658

659

660

661

662

663

664

665

666

667

668

669

670

671

672

673

674

675

676

677

678

679

680

681
UNICEF 2019, Gender Counts: East and Southeast Asia: A quantitative assessment of gender inequality and its impact on girls and boys, UNICEF East Asia \& Pacific, $<$ https://www.unicef.org/eap/reports/gender-counts-east-and-southeast-asia>.

USAID The DHS Program- Demographic and Health Surveys available datasets, 25 March 2018, $<$ https://dhsprogram.com/data/available-datasets.cfm>.

USAID 2015, Unmet Need for Family Planning-Family Planning and Reproductive Health Indicators, , $<$ https://www.measureevaluation.org/prh/rh indicators/family-planning/fp/unmet-need-for-familyplanning>.

Vong, S 2008, 'Knowledge, Attitude and Practice (KAP) of Family Planning among Married Women in Banteay Meanchey, Cambodia', Ritsumeikan J Asia Pac Stud, vol. 27, pp. 103-16.

Webber, GC, Spitzer, DL, Somrongthong, R, Dat, TC \& Kounnavongsa, S 2015, 'Migrant Beer Promoters' Experiences Accessing Reproductive Health Care in Cambodia, Laos, Thailand, and Vietnam: Lessons for Planners and Providers', Asia-Pacific Journal of Public Health, vol. 27, no. 2, pp. NP1228-NP40.

WHO 2012, Making health services adolescent friendly: Developing national quality standards for adolescent friendly health services, Switzerland, <https://www.who.int/maternal child adolescent/documents/adolescent friendly services/en/>.

WHO 2015, Health in 2015: From MDGs, millennium development goals to SDGs, sustainable development goals, <https://www.who.int/gho/publications/mdgs-sdgs/en/>.

WHO 2017, Cambodia- Identifying actions for scaling up long-lasting reversible contraceptives, <https://iris.wpro.who.int/bitstream/handle/10665.1/13834/9789290618218 eng.pdf>.

Wulifan, JK, Brenner, S, Jahn, A \& De Allegri, M 2015, 'A scoping review on determinants of unmet need for family planning among women of reproductive age in low and middle income countries', $B M C$ Women's Health, vol. 16, no. 1, p. 2. 


\title{
Box 1(on next page)
}

\author{
Policy implications
}




\section{What is already known}

In Cambodia in 2014, 33\% of Cambodian females aged 15-24 years have been using modern contraception methods and $13 \%$ females have been using traditional methods. There is a gap between knowledge and use of contraception.

\section{What this study adds}

There is an increased likelihood of unmet need for contraception in adolescent girls aged 15-19 years and young women aged 20-24 years compared to 25-29-year-old women. Unmet need in Cambodian females aged 15-29 years is associated with increased parity, unemployment, and low personal autonomy for accessing healthcare and deciding about the family size.

\section{What insights does this study provide for informing policy decision-making}

There is a need to implement culturally appropriate policies for increased SRH literacy, education, and employment opportunities to improve gender equity. Cambodia can achieve the targets set for Sustainable Development Goal 3 as proposed by the United Nations for gender equality, and improved autonomy of women by implementing relevant policy and legal frameworks for;

- SRH literacy programs

- Equal opportunity education and employment prospects to reduce gender gaps

- Linking programs for adolescents' SRH and referral between schools and health facilities

- Reducing child marriages and improving access to modern contraception for youth in the community

- Dissemination of SRH information via mobile-phone based text messages, social media and community-outreach programs

- Increasing awareness for short-acting modern contraceptives and focusing on condom use due to the dual protection

- Reducing barriers at the user, health systems and policy levels for promoting long-acting reversible contraceptives (LARCS) including subdermal implants for females

- Ensuring acceptable, affordable and targeted adolescent and youth friendly SRH services 
Table $\mathbf{1}$ (on next page)

Sociodemographic details 
1 Table 1: Sociodemographic characteristics of participants aged 15-29 years

2 Dataset obtained from Cambodian Demographic and Health Survey $2014(N=4823)$

\begin{tabular}{|c|c|c|c|c|c|}
\hline & Variables & $\begin{array}{l}\text { Age group } \\
15-19 \text { years }\end{array}$ & $\begin{array}{l}\text { Age group } \\
20-24 \text { years }\end{array}$ & $\begin{array}{l}\text { Age group } \\
25-29 \text { years }\end{array}$ & Total \\
\hline 1 & $\begin{array}{l}\text { Education } \\
\text { Higher } \\
\text { Secondary } \\
\text { Primary } \\
\text { No education } \\
\text { Total }\end{array}$ & $\begin{array}{l}3(0.6 \%) \\
242(47.2 \%) \\
225(43.9 \%) \\
42(8.2 \%) \\
512(100 \%)\end{array}$ & $\begin{array}{l}76(4.0 \%) \\
866(45.7 \%) \\
800(42.3 \%) \\
151(8.0 \%) \\
1893(100 \%)\end{array}$ & $\begin{array}{l}151(6.2 \%) \\
842(34.8 \%) \\
1129(46.7 \%) \\
296(12.2 \%) \\
2418(100 \%)\end{array}$ & $\begin{array}{l}230(4.7 \%) \\
1950(40.4 \%) \\
2154(44.6 \%) \\
489(10.1 \%) \\
4823(100 \%)\end{array}$ \\
\hline 2 & $\begin{array}{l}\text { Wealth index } \\
\text { Richest } \\
\text { Richer } \\
\text { Middle } \\
\text { Poorer } \\
\text { Poorest } \\
\text { Total }\end{array}$ & $\begin{array}{l}88(17.2 \%) \\
100(19.5 \%) \\
99(19.3 \%) \\
111(21.7 \%) \\
114(22.3 \%) \\
512(100 \%)\end{array}$ & $\begin{array}{l}455(20.0 \%) \\
355(18.7 \%) \\
337(17.8 \%) \\
348(18.4 \%) \\
398(21.0 \%) \\
1893(100 \%)\end{array}$ & $\begin{array}{l}681(28.2 \%) \\
462(19.1 \%) \\
379(15.7 \%) \\
451(18.6 \%) \\
445(18.4 \%) \\
2418(100 \%)\end{array}$ & $\begin{array}{l}1224(25.4 \%) \\
917(19.0 \%) \\
815(16.9 \%) \\
910(18.8 \%) \\
957(19.8 \%) \\
4823(100 \%)\end{array}$ \\
\hline 3 & $\begin{array}{l}\text { Marital status } \\
\text { Never in union } \\
\text { Married } \\
\text { Living with partner } \\
\text { Widowed } \\
\text { Divorced } \\
\text { Separated (No longer living } \\
\text { together) } \\
\text { Total }\end{array}$ & $\begin{array}{l}15(2.9 \%) \\
458(89.4 \%) \\
8(1.5 \%) \\
2(0.4 \%) \\
21(4.1 \%) \\
8(1.5 \%) \\
512(100 \%)\end{array}$ & $\begin{array}{l}24(1.3 \%) \\
1722(90.9 \%) \\
21(1.1 \%) \\
34(1.8 \%) \\
75(4.0 \%) \\
17(0.9 \%)\end{array}$ & $\begin{array}{l}8(0.3 \%) \\
2221(91.8 \%) \\
20(0.8 \%) \\
38(1.5 \%) \\
122(5.0 \%) \\
9(0.3 \%)\end{array}$ & $\begin{array}{l}47(0.9 \%) \\
4401(91.2 \%) \\
49(1.0 \%) \\
74(1.5 \%) \\
218(4.5 \%) \\
34(0.7 \%) \\
4823(100 \%)\end{array}$ \\
\hline
\end{tabular}




\begin{tabular}{|c|c|c|c|c|c|}
\hline & & & $1893(100 \%)$ & $2418(100 \%)$ & \\
\hline 4 & $\begin{array}{l}\text { Current employment } \\
\text { Yes } \\
\text { No } \\
\text { Total }\end{array}$ & $\begin{array}{l}304(59.3 \%) \\
208(40.6 \%) \\
512(100 \%)\end{array}$ & $\begin{array}{l}1190(62.8 \%) \\
703(37.1 \%) \\
1893(100 \%)\end{array}$ & $\begin{array}{l}1737(71.8 \%) \\
680(28.1 \%) \\
2418(100 \%)\end{array}$ & $\begin{array}{l}3231(67.0 \%) \\
1591(33.0 \%) \\
4822(100 \%)\end{array}$ \\
\hline 5 & $\begin{array}{l}\text { Current contraception method } \\
\text { used } \\
\text { Modern methods } \\
\text { Traditional methods } \\
\text { No contraception used } \\
\text { Total }\end{array}$ & $\begin{array}{l}91(17.7 \%) \\
35(6.8 \%) \\
386(75.3 \%) \\
512(100 \%)\end{array}$ & $\begin{array}{l}629(33.2 \%) \\
245(13 \%) \\
1019(53.8 \%) \\
1893(100 \%)\end{array}$ & $\begin{array}{l}986(40.7 \%) \\
378(15.6 \%) \\
1054(43.5 \%) \\
2418(100 \%)\end{array}$ & $\begin{array}{l}1706(35.4 \%) \\
658(13.6 \%) \\
2459(51.0 \%) \\
4823(100 \%)\end{array}$ \\
\hline 6 & $\begin{array}{l}\text { Parity } \\
\text { No children } \\
1-2 \text { children } \\
3 \text { or more children } \\
\text { Total }\end{array}$ & $\begin{array}{l}281(54.9 \%) \\
230(44.9 \%) \\
1(0.2) \\
512(100 \%)\end{array}$ & $\begin{array}{l}453(23.9 \%) \\
1385(73.2 \%) \\
55(2.9 \%) \\
1893(100 \%)\end{array}$ & $\begin{array}{l}241(10.0 \%) \\
1750(72.4 \%) \\
427(17.6 \%) \\
2418(100 \%)\end{array}$ & $\begin{array}{l}975(20.2 \%) \\
3365(69.8 \%) \\
483(10.0 \%) \\
4823(100 \%)\end{array}$ \\
\hline 7 & $\begin{array}{l}\text { Unmet need for contraception } \\
\text { Yes } \\
\text { No } \\
\text { Total }\end{array}$ & $78(15.2 \%)$ & $\begin{array}{l}230(12.1 \%) \\
1663(87.9 \%) \\
1893(100 \%)\end{array}$ & $\begin{array}{l}256(10.6 \%) \\
2162(89.4 \%) \\
2418(100 \%)\end{array}$ & $\begin{array}{l}564(11.7 \%) \\
4259(88.3 \%) \\
4823(100 \%)\end{array}$ \\
\hline 8 & $\begin{array}{l}\text { Knowledge of ovulatory cycle } \\
\text { Correct information } \\
\text { (Middle of two menstrual cycles) } \\
\text { Incorrect information } \\
\text { (during periods, before periods, at }\end{array}$ & $\begin{array}{l}77(15.0 \%) \\
93(18.2 \%)\end{array}$ & $\begin{array}{l}405(21.4 \%) \\
325(17.2 \%)\end{array}$ & $\begin{array}{l}655(27.1 \%) \\
403(16.6 \%)\end{array}$ & $\begin{array}{l}1137(23.6 \%) \\
821(17.0 \%)\end{array}$ \\
\hline
\end{tabular}




\begin{tabular}{|c|c|c|c|c|c|}
\hline & $\begin{array}{l}\text { any time) } \\
\text { Do not know } \\
\text { Total }\end{array}$ & $\begin{array}{l}342(66.8 \%) \\
512(100 \%)\end{array}$ & $\begin{array}{l}1162(61.4 \%) \\
1892(100 \%)\end{array}$ & $\begin{array}{l}1360(56.3 \%) \\
2418(100 \%)\end{array}$ & $\begin{array}{l}2864 \text { (59.4\%) } \\
4822(100 \%)\end{array}$ \\
\hline 9 & $\begin{array}{l}\text { Respondent can ask } \\
\text { partner/husband to use a condom } \\
\text { at sexual intercourse }(\mathrm{N}=4450) \\
\text { Yes } \\
\text { No } \\
\text { Do not know } \\
\text { Total }\end{array}$ & $\begin{array}{l}372(79.8 \%) \\
48(10.3 \%) \\
46(9.9 \%) \\
466(100 \%)\end{array}$ & $\begin{array}{l}1503(86.2 \%) \\
122(7.0 \%) \\
118(6.8 \%) \\
1743(100 \%)\end{array}$ & $\begin{array}{l}1936(86.4 \%) \\
153(6.8 \%) \\
152(6.8 \%) \\
2241(100 \%)\end{array}$ & $\begin{array}{l}3811(85.6 \%) \\
323(7.2 \%) \\
316(7.1 \%) \\
4450(100 \%)\end{array}$ \\
\hline 10 & $\begin{array}{l}\text { Person deciding about woman's } \\
\text { access to healthcare ( } \mathbf{N}=\mathbf{4 4 4 8} \text { ) } \\
\text { Respondent and husband together } \\
\text { Husband alone } \\
\text { Someone else in the family } \\
\text { Respondent alone } \\
\text { Total }\end{array}$ & $\begin{array}{l}244(52.4 \%) \\
38(8.2 \%) \\
8(1.7 \%) \\
175(37.6 \%) \\
465(100 \%)\end{array}$ & $\begin{array}{l}862(49.5 \%) \\
153(8.8 \%) \\
18(1.0 \%) \\
709(40.7 \%) \\
1742(100 \%)\end{array}$ & $\begin{array}{l}1134(50.6 \%) \\
164(7.3 \%) \\
11(0.5 \%) \\
932(41.5 \%) \\
2241(100 \%)\end{array}$ & $\begin{array}{l}2240(50.3 \%) \\
355(8.0 \%) \\
37(0.8 \%) \\
1816(40.8 \%) \\
4448(100 \%)\end{array}$ \\
\hline 11 & $\begin{array}{l}\text { Person deciding about major } \\
\text { household items purchase } \\
\text { (N=4446) } \\
\text { Respondent and husband together } \\
\text { Husband alone } \\
\text { Someone else in the family } \\
\text { Respondent alone }\end{array}$ & $\begin{array}{l}354(76.1 \%) \\
32(6.9 \%) \\
20(4.3 \%) \\
59(12.7 \%)\end{array}$ & $\begin{array}{l}1363(78.3 \%) \\
88(5.0 \%) \\
47(2.7 \%) \\
242(13.9 \%)\end{array}$ & $\begin{array}{l}1771(79.0 \%) \\
103(4.6 \%) \\
25(1.1 \%) \\
342(15.2 \%)\end{array}$ & $\begin{array}{l}3488(78.4 \%) \\
223(5.0 \%) \\
92(2.1 \%) \\
643(14.4 \%)\end{array}$ \\
\hline
\end{tabular}




\begin{tabular}{|c|c|c|c|c|c|}
\hline & Total & 465 (100\%) & 1740 (100\%) & 2241 (100\%) & 4446 (100\%) \\
\hline 12 & $\begin{array}{l}\text { Decision for family size }(\mathrm{N}=\mathbf{4 4 2 2} \text { ) } \\
\text { Husband wants more children } \\
\text { Husband wants fewer children } \\
\text { Both want same number of children } \\
\text { Do not know } \\
\text { Total }\end{array}$ & $\begin{array}{l}66(14.2 \%) \\
10(2.1 \%) \\
319(68.6 \%) \\
70(15.0 \%) \\
465(100 \%)\end{array}$ & $\begin{array}{l}274(15.8 \%) \\
93(5.3 \%) \\
1162(66.8 \%) \\
209(12.0 \%) \\
1738(100 \%)\end{array}$ & $\begin{array}{l}419(18.9 \%) \\
135(6.1 \%) \\
1465(66.0 \%) \\
200(9.0 \%) \\
2219(100 \%)\end{array}$ & $\begin{array}{l}759(17.1 \%) \\
238(5.4 \%) \\
2946(66.6 \%) \\
479(10.8 \%) \\
4422(100 \%)\end{array}$ \\
\hline 13 & $\begin{array}{l}\text { Participants heard about family } \\
\text { planning media messages on radio } \\
\text { in the last three months } \\
\text { Yes } \\
\text { No } \\
\text { Total }\end{array}$ & $166(32.4 \%)$ & $\begin{array}{l}691(36.5 \%) \\
1201(63.5 \%) \\
1892(100 \%)\end{array}$ & $\begin{array}{l}918(38.0 \%) \\
1500(62.0 \%) \\
2418(100 \%)\end{array}$ & $\begin{array}{l}1775(36.8 \%) \\
3047(63.2 \%) \\
4822(100 \%)\end{array}$ \\
\hline 14 & $\begin{array}{l}\text { Participants heard about family } \\
\text { planning media messages on } \\
\text { television in the last three months } \\
\text { Yes } \\
\text { No } \\
\text { Total }\end{array}$ & $210(41.0 \%)$ & $\begin{array}{l}905(47.8 \%) \\
987(52.2 \%) \\
1892(100 \%)\end{array}$ & $\begin{array}{l}1263(52.2 \%) \\
1155(47.8 \%) \\
2418(100 \%)\end{array}$ & $\begin{array}{l}2378(49.3 \%) \\
2444(50.7 \%) \\
4822(100 \%)\end{array}$ \\
\hline 15 & $\begin{array}{l}\text { Accessible distance to health } \\
\text { facility and getting medical help for } \\
\text { herself ( } N=4823) \\
\text { Not difficult } \\
\text { Very difficult } \\
\text { Total }\end{array}$ & $\begin{array}{l}323(63.0 \%) \\
189(37.0 \%) \\
512(100 \%)\end{array}$ & $\begin{array}{l}1207(63.8 \%) \\
686(36.2 \%) \\
1893(100 \%)\end{array}$ & $\begin{array}{l}1630(67.4 \%) \\
788(32.6 \%) \\
2418(100 \%)\end{array}$ & $\begin{array}{l}3160(65.5 \%) \\
1663(34.5 \%) \\
4823(100 \%)\end{array}$ \\
\hline
\end{tabular}

$3 \quad * *$ Traditional contraception methods include; withdrawal method or coitus interruptus, abstinence, rhythm or calendar method, and other folk methods reported by the respondent including tinctures, potions, and herbs.

$5 \quad * * *$ Modern contraception methods include' a) reversible methods used for short duration including oral contraceptive hormonal pills for 6 continued monthly use, emergency contraceptive pill (morning after pill), and male and female condoms, and b) long acting reversible 7 contraceptives (LARCs); intrauterine contraceptive devices (IUCDs), hormonal injectables, dermal implants, and c) non-reversible, permanent 8 modern contraceptive methods including female and male sterilization.(National Institute of Statistics/Cambodia, 2015, and Cahill et al 2018, 9 Lancet). 
10 \#* There are missing values in some variables and total number $(\mathrm{N})$ is shown in the table. There are missing values of 407 women in the two

11 variables, "person to decide for respondent's health care" and "person deciding about major household items purchase" in the dataset

12 
Table 2 (on next page)

Bivariate analyses 
1 Table 2: Bivariate analyses of unmet need for contraception in Cambodian females aged 15-29

2 years

3

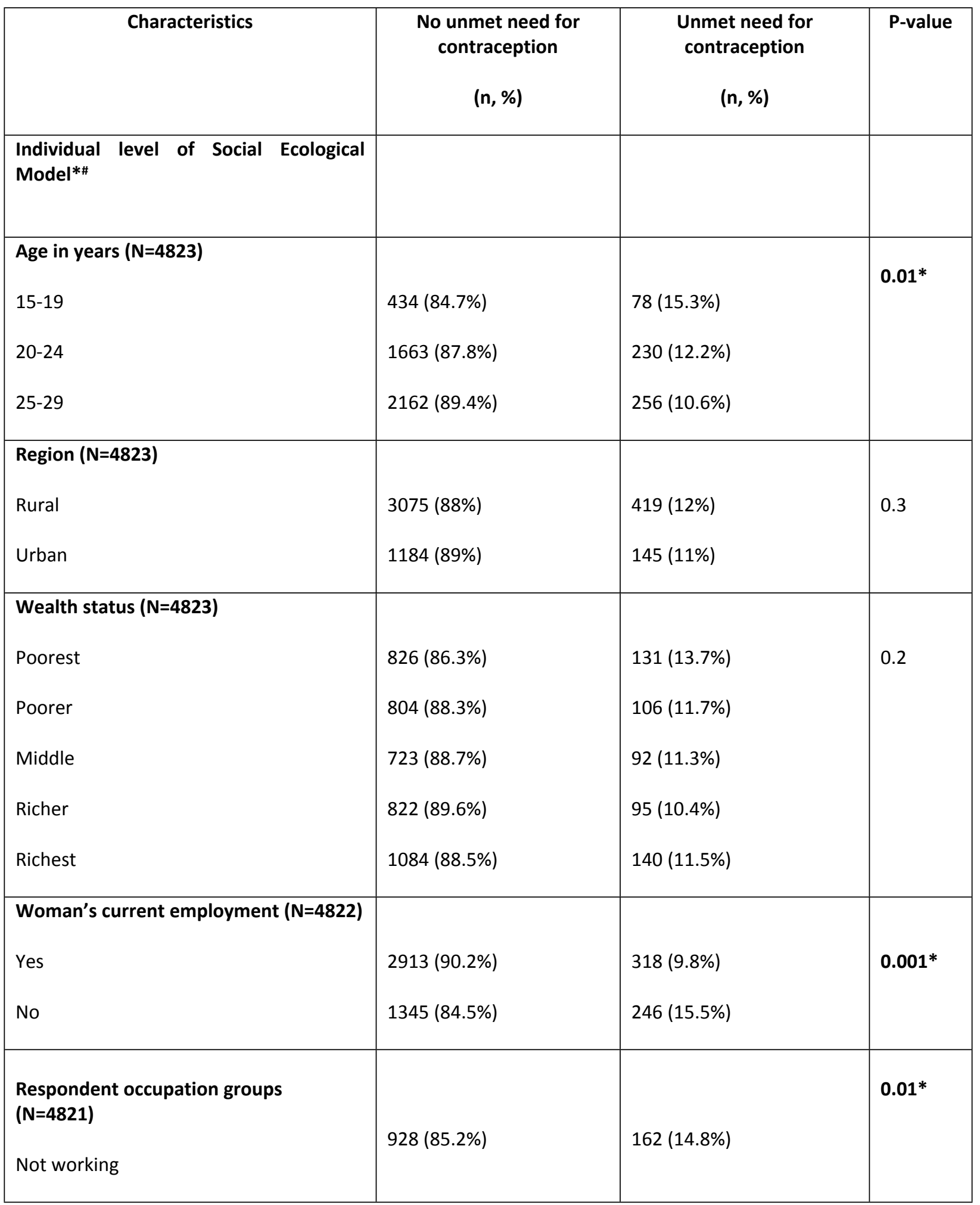




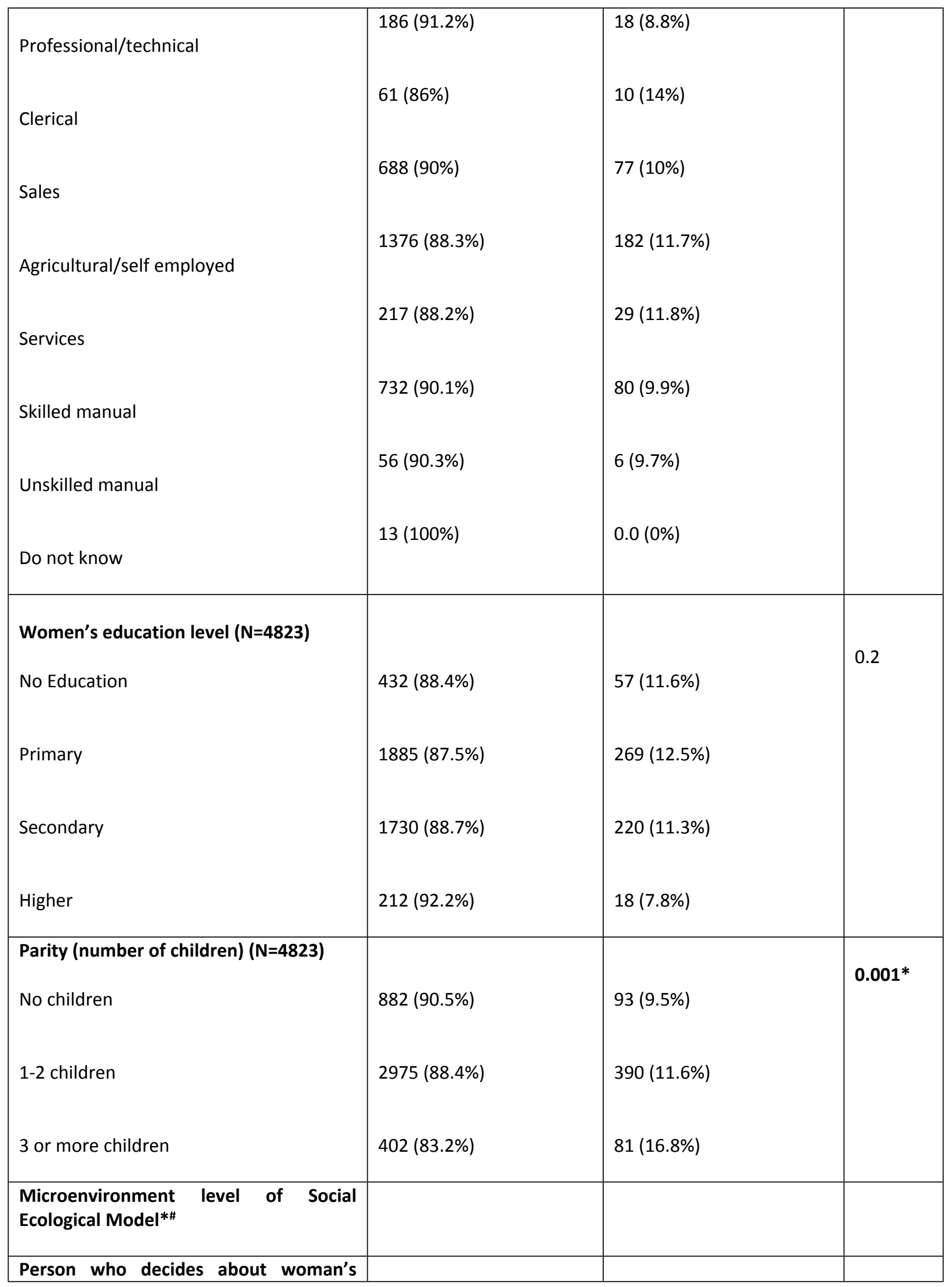




\begin{tabular}{|c|c|c|c|}
\hline access to healthcare $(\mathrm{N}=4448)$ & & & 0.1 \\
\hline Respondent & $1585(87.3 \%)$ & 231 (12.7\%) & \\
\hline Together (husband and wife) & 1975 (88.2\%) & 265 (11.8\%) & \\
\hline Husband only & $315(88.7 \%)$ & 40 (11.3\%) & \\
\hline $\begin{array}{l}\text { Someone else in the household } \\
\text { (mother/parent in law) }\end{array}$ & $28(75.7 \%)$ & $9(24.3 \%)$ & \\
\hline $\begin{array}{l}\text { Person who decides about purchasing } \\
\text { major household items }(\mathrm{N}=4446)\end{array}$ & & & $0.01 *$ \\
\hline Respondent & 557 (86.6\%) & $86(13.4 \%)$ & \\
\hline Together (husband and wife) & $3076(88.2 \%)$ & $412(11.8 \%)$ & \\
\hline Husband only & $198(88.8 \%)$ & 25 (11.2\%) & \\
\hline $\begin{array}{l}\text { Someone else in the household } \\
\text { (mother/parent in law) }\end{array}$ & $71(77.2 \%)$ & $21(22.8 \%)$ & \\
\hline $\begin{array}{l}\text { Decision for family size } \\
(\mathrm{N}=4422)\end{array}$ & 2610100601 & & $0.01 *$ \\
\hline & 649 (85.5\%) & 110 (14.5\%) & \\
\hline Husband wants less children & $213(89.5 \%)$ & $25(10.5 \%)$ & \\
\hline Do not know & 405 (84.5\%) & 74 (15.4\%) & \\
\hline $\begin{array}{l}\text { Macroenvironment level of Social } \\
\text { Ecological Model*\# }\end{array}$ & & & \\
\hline $\begin{array}{l}\text { Participants heard about family planning } \\
\text { media messages on radio in the last } \\
\text { three months ( } \mathrm{N}=4822 \text { ) } \\
\text { Yes }\end{array}$ & & & \\
\hline & $1575(88.7 \%)$ & $200(11.3 \%)$ & 0.4 \\
\hline
\end{tabular}




\begin{tabular}{|l|l|l|l|}
\hline No & $2683(88 \%)$ & $364(12 \%)$ & \\
\hline $\begin{array}{l}\text { Participants heard about family planning } \\
\text { media messages on television in the last } \\
\text { three months (N=4822) }\end{array}$ & $2112(88.8 \%)$ & $266(11.2 \%)$ & 0.2 \\
Yes & $2146(87.8 \%)$ & $298(12.2 \%)$ & 0.2 \\
\hline $\begin{array}{l}\text { No } \\
\text { getting medical help for herself } \\
\text { (N=4823) }\end{array}$ & $2805(88.8 \%)$ & $355(11.2 \%)$ & \\
Not difficult & $1454(87.4 \%)$ & $209(12.6 \%)$ & \\
\hline \begin{tabular}{l} 
Very difficult \\
\hline
\end{tabular}
\end{tabular}

Pearson Chi square test was used as the statistical test of significance

5 Dataset obtained from Cambodian Demographic and Health Survey $2014(\mathrm{~N}=4823)$, but there are some missing values in some variables in the

6 dataset.

$7 \quad{ }^{*}$ p-value is significant if $<0.05$

8 *\# Bronfenbrenner's Social Ecological Model used as theoretical framework: Individual level (intrapersonal level including age, knowledge, 9 attitudes, beliefs, practices; area of residence; employment; education and wealth status; Microenvironment level (interpersonal level including partners and peers; institutional and community level; Macroenvironment level (policy enabling, laws) 
Table 3 (on next page)

Binary logistic regression analyses 
1 Table 3: Binary logistic regression analyses showing factors influencing unmet need for 2 contraception in sexually active Cambodian females aged 15-29 years

3

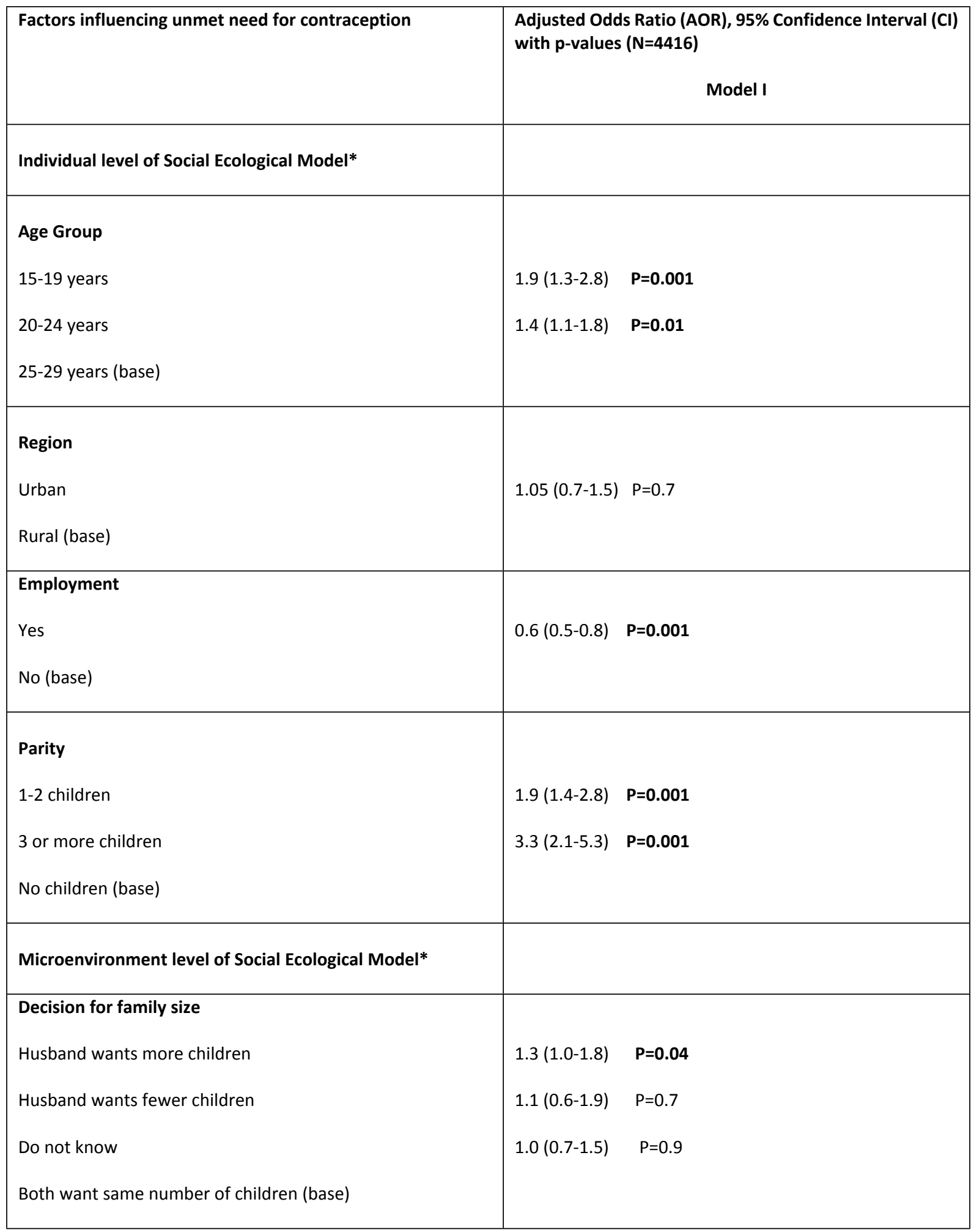




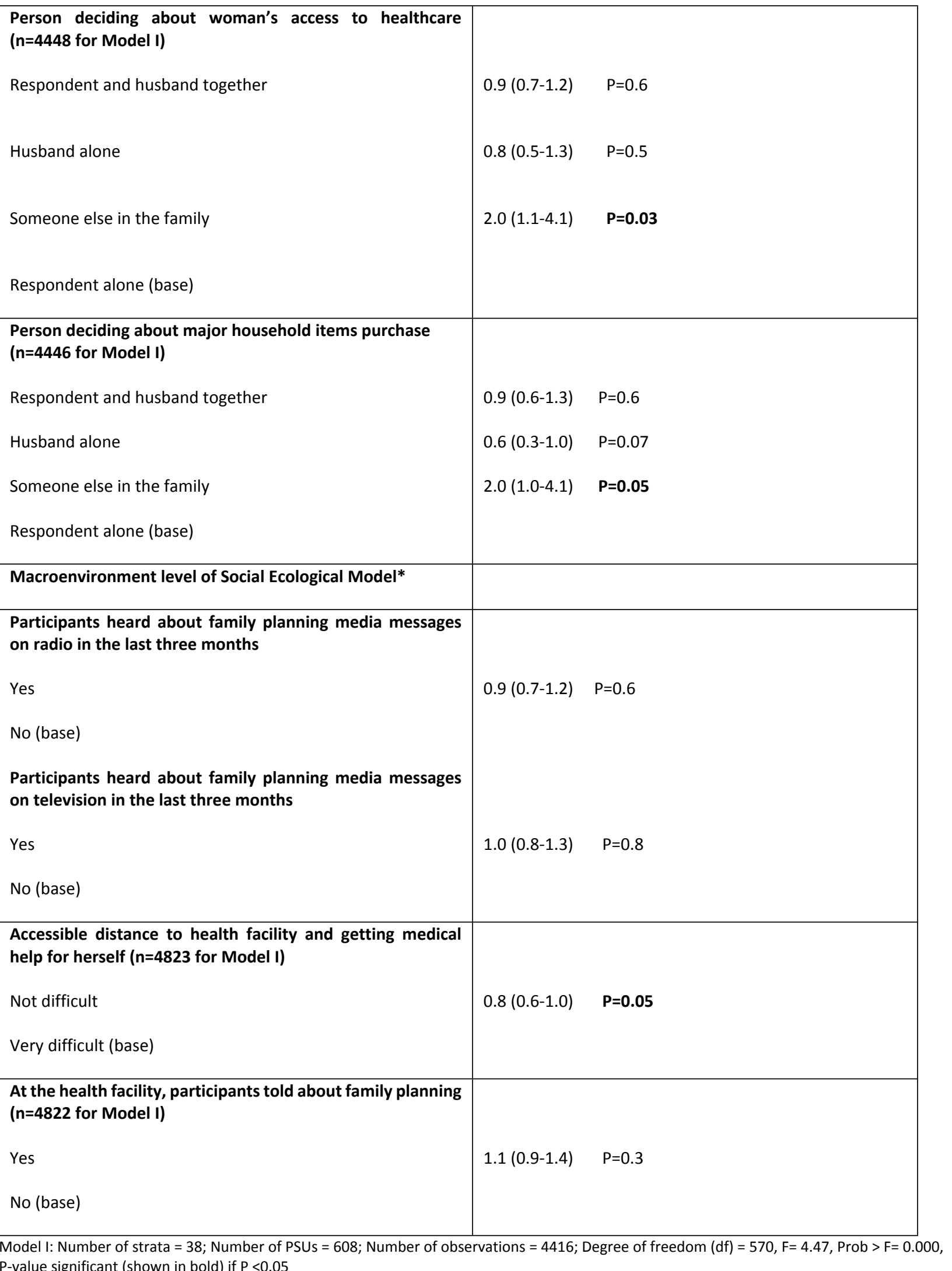


6 *Bronfenbrenner's social ecological model used as theoretical framework with three levels (Individual level, microenvironment level,

7 macroenvironment level

$8 \quad * *$ Hosmer-Lemeshaw goodness-of-fit test for logistic model: $F(9,562)=0.8$, Prob $>F=0.6$

$9 \quad * * *$ Data used from 2014 Cambodian Demographic and Health Survey (CDHS)

10 \#* There are 407 missing values in the variables "person to decide for respondent's health care" and "person deciding about major household 11 item purchase" in the dataset 
Figure 1

Social Ecological Model for factors influencing unmet need for contraception in sexually active, single, in union, or married adolescent girls and women aged 15-29 years in Cambodia 


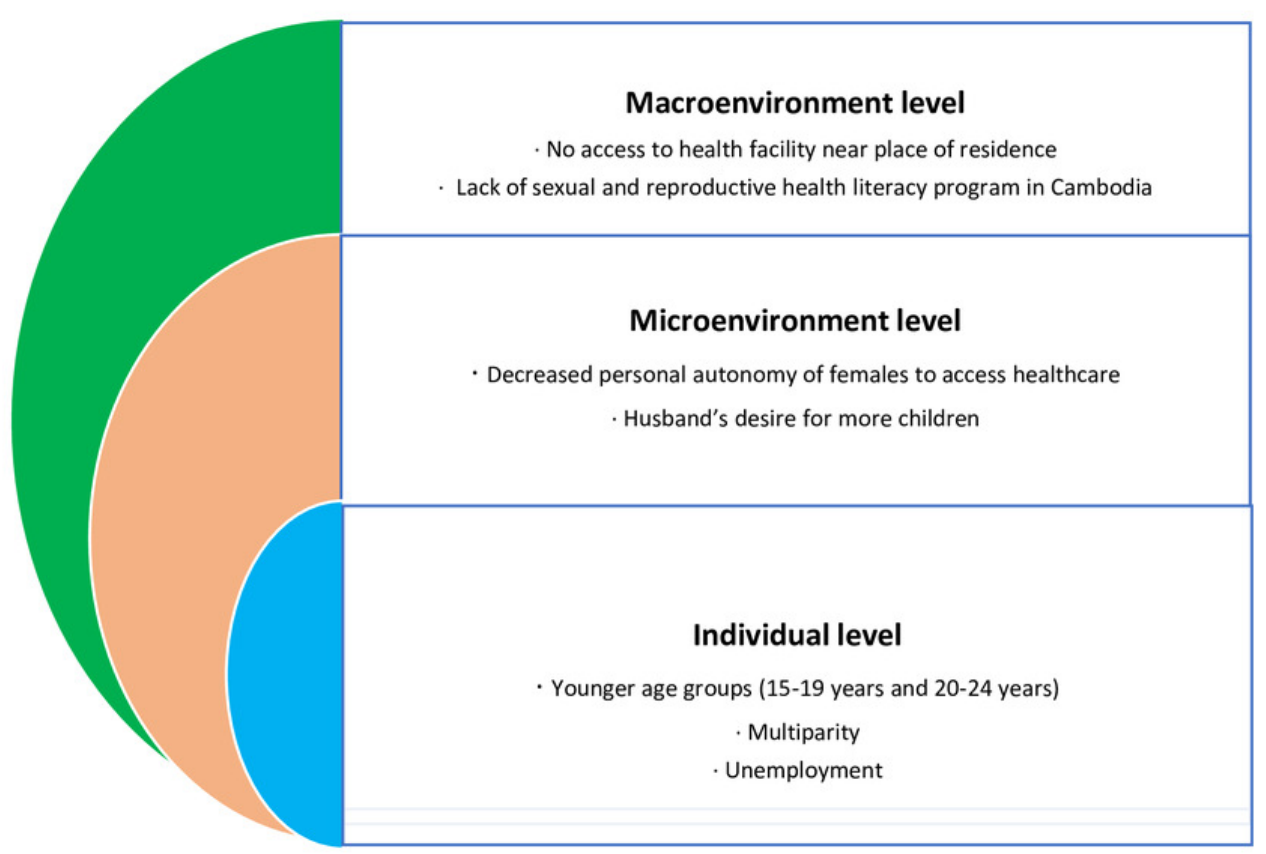

